\title{
Timing of Expression of Inflammatory Mediators in Skeletal Muscles from Mice Acutely Infected with the RA Strain of Trypanosoma cruzi
}

\author{
Romina Andrea Cutrullis ${ }^{a}$ Miriam Postan ${ }^{b}$ Patricia Beatriz Petray ${ }^{a}$ \\ Ricardo Santiago Corral ${ }^{a}$ \\ aServicio de Parasitología y Chagas, Hospital de Niños Dr. Ricardo Gutiérrez, and b Instituto Nacional de \\ Parasitología Dr. Mario Fatala Chabén/ANLIS/Malbrán, Buenos Aires, Argentina
}

\section{Key Words}

Acute infection - Chagas disease - Chemokines •

Inflammation · Skeletal muscles · Trypanosoma cruzi

\begin{abstract}
Objective: Chagas' disease is caused by persistent Trypanosoma cruzi infection in muscle cells that ultimately results in chronic inflammation and tissue destruction. The goal of this study was to determine the expression of different chemokines and their receptors, as well as proinflammatory cytokines and inducible nitric oxide synthase, in muscles from mice acutely infected with T. cruzi. Methods: Histological, semiquantitative reverse transcriptase polymerase chain reaction and immunohistochemical studies were performed on skeletal muscle and myocardium of BALB/c mice infected with T. cruzi, RA strain. Results: Early induction of muscular mRNA expression for CCL5/CCR5 and CXCL9/CXCR3, as well as for iNOS, IFN- $\gamma$, TNF- $\alpha$ and MIF, was demonstrated accompanied by progressive increases in parasitism and leukocyte recruitment. Protein overexpression for MIF and CCL5/CCR5 was also verified in the infected muscles. Conclusions: In muscles from acutely T. cruzi RA-infected mice, upregulated gene expression of proinflammatory chemokines, chemokine receptors, cytokines and iNOS is associated with the severity of parasite burden and myopathic alterations. Compared to the heart, striated muscles displayed differential
\end{abstract}

timing of expression of several inflammatory mediators throughout acute infection. Our findings suggest that enhanced early production of these factors could contribute to T. cruzi-dependent inflammatory damage to skeletal muscles.

Copyright ๑ 2009 S. Karger AG, Basel

\section{Introduction}

Chagas' disease, caused by the intracellular protozoan parasite Trypanosoma cruzi, is one of the most important public health problems in Latin America. The overall prevalence of this human infection is estimated at 16-18 million cases, with 100 million at risk for infection [1]. The acute phase of infection is characterized by the presence of parasites in the bloodstream and diverse host tissues. Parasite replication is hampered during this stage by both innate and acquired immune responses mediated by macrophages, NK cells, B cells, CD4+ and CD8+ T cells [2]. Proinflammatory cytokines (e.g. IFN- $\gamma$, TNF- $\alpha$ and IL-12) also play a crucial role in protective immunity against T. cruzi [3]. IL-12 enhances IFN- $\gamma$ production from NK and T cells. IFN- $\gamma$ combined with TNF- $\alpha$ will

P.B.P. and R.S.C. contributed equally to this work.

\section{KARGER}

Fax +4161306 1234 E-Mail karger@karger.ch www.karger.com
(C) 2009 S. Karger AG, Basel

1015-2008/09/0764-0170\$26.00/0

Accessible online at:

www.karger.com/pat
Dr. Ricardo S. Corral

Servicio de Parasitología y Chagas

Hospital de Niños Dr. Ricardo Gutiérrez

Gallo 1330, Buenos Aires 1425 (Argentina)

Tel./Fax +54 114963 4122, E-Mail ricardocorral56@hotmail.com 
generate resistance to $T$. cruzi infection by activating phagocytes to release high levels of reactive nitrogen intermediates, such as NO, that are toxic to the parasite [2, 4]. Recently, MIF, a pleiotropic proinflammatory cytokine capable of inducing type 1 immune responses, was also demonstrated to be a key element for host defense in mice with acute T. cruzi infection [5]. This complex microbicidal reaction is helpful in controlling parasitemia but, on the other hand, may also provoke toxic lesions in the host [2].

After development of immunity, both parasitemia and tissue parasitism are controlled. However, $20-30 \%$ of patients chronically infected with $T$. cruzi will develop severe neuromuscular disorders many years after the initial infection by a yet undefined mechanism. Cardiomyopathy is considered the most distinctive clinical entity associated with Chagas' disease in symptomatic chronic patients [6]. Nevertheless, around $60 \%$ of subjects chronically infected with T. cruzi present skeletal muscle inflammatory pathology [7]. Several hypotheses have been raised to explain the pathogenesis of Chagas' disease, including the persistency of the parasite or its antigens at the target organ and/or the contribution of an autoimmune process [8]. Regardless of the causative mechanisms, previous studies indicate that the intensity of pathophysiological alterations that occur at early stages of $T$. cruzi infection correlates positively with the severity of cardiomyopathy observed at the chronic phase of Chagas' disease [9].

Infiltration of $\mathrm{T}$ cells and macrophages into target sites such as the heart and skeletal muscle during acute infection is essential for reducing cardiac and muscular parasitism [10]. Nevertheless, continued local inflammation leads to chagasic cardiomyopathy and neuromyopathic lesions [11]. Chemokines and their cognate receptors orchestrate the normal trafficking of leukocytes to both lymphoid and nonlymphoid tissues and may selectively recruit cells into sites of antigenic challenge. In addition, chemokines have been shown to direct the influx of cells in a variety of experimental infections where they participate in the control of pathogens and/or in chronic inflammation [12]. Parasite antigens and/or DNA, as well as cytokines known to participate in resistance to T. cru$z i$ infection, are able to modulate the expression of inflammatory chemokines and their receptors $[13,14]$. It has been proposed that IFN- $\gamma$-elicited chemoattractants present in T. cruzi-infected heart create a favorable environment for selective and preferential migration of CD8+ $\mathrm{T}$ cells towards this tissue, enhancing parasite elimination, but also leading to myocarditis [15]. This has been described as a rather precocious process, being detected during the early acute phase. Several studies have revealed that T. cruzi-infected macrophages as well as cardiomyocytes produce the CC chemokines CCL2, CCL3, CCL4 and CCL5. Further, increased levels of mRNA encoding for the above-mentioned chemokines, the chemokine receptor CCR5 and the CXC chemokines CXCL1, CXCL2, CXCL3, CXCL9 and CXCL10 have been detected in cardiac tissues from acutely and chronically T. cruziinfected mice, implicating a potential role for these molecules in Chagas' disease $[16,17]$. $\mathrm{T}$ cells, mostly CD8+CCR5+, were frequently observed in leukocyte infiltrates present in the myocardium of trypanosome-infected rodents [17]. Interestingly, CCR5 was also overexpressed on CD8+ peripheral blood T cells from patients with chagasic cardiomyopathy compared with uninfected individuals [18].

Unlike the situation observed in cardiac tissues, the production of proinflammatory cytokines and chemokines in striated muscles from T. cruzi-infected hosts has been poorly explored. The present study was undertaken to evaluate expression levels of different members of the $\mathrm{CC}$ and CXC chemokine subfamilies and receptors, as well as proinflammatory cytokines and iNOS, in skeletal muscle during the initial stage of murine infection with the RA strain of T. cruzi, capable of triggering neuromyopathic damage [19].

\section{Materials and Methods}

\section{Animals}

Six- to 8 -week-old female BALB/c mice were obtained from the Centro Nacional de Energía Atómica (Buenos Aires, Argentina) and maintained under standard conditions in the animal house of the 'Dr. Ricardo Gutiérrez' Children's Hospital (Buenos Aires, Argentina). All experiments in this study were performed according to the National Research Council's guide for animal care.

Parasites and Experimental Infection

The RA strain of T. cruzi, originally isolated from an acute Chagas patient [20], was used in all in vivo experiments. The strain is maintained by serial passages in outbred mice at the University of Buenos Aires. Animals were infected intraperitoneally with 50 blood-derived trypomastigotes of T. cruzi RA. Parasitemia was measured every 2 days in $5 \mu$ l of tail vein blood examined microscopically at $\times 400$ magnification.

\section{Histologic Evaluation}

Groups of 5 animals were sacrificed under ether anesthesia at various time intervals after T. cruzi infection $(0,7,14,21$ and 28 days post-infection, DPI). Hearts and skeletal muscle from rear legs were removed, sectioned and stored under specific conditions for diverse assays. One part of a tissue sample was fixed in neutral 
formalin, embedded in paraffin, sectioned, stained with hematoxylin and eosin and examined by light microscopy. A doubleblind evaluation of the specimens was performed on randomized, precoded slides in a systematic fashion. Heart sections were examined for the presence of intracellular parasites and inflammation, which were quantified as described previously [21]. Briefly, different regions of the organ were scored on a scale of $0-4$ according to the severity and extent of the inflammation (normal = 0 , focal $=1$, multifocal $=2$, diffuse with partial wall involvement $=3$, total wall involvement $=4$ ). Tissue parasites and inflammation in skeletal muscle were determined in 10 randomly selected fields at $\times 200$ magnification.

\section{Semiquantitative Reverse Transcriptase Polymerase Chain} Reaction (RT-PCR)

Total RNA was isolated from skeletal muscle and cardiac tissue of mice using TRIzol ${ }^{\mathrm{TM}}$ (Invitrogen, Life Technologies, Carlsbad, Calif., USA) reagent according to the manufacturer's specifications. Five micrograms of total RNA were reverse transcribed by the addition of $1 \mathrm{U}$ of Moloney murine leukemia virus RNAase H-reverse transcriptase (MMLV, Promega, Madison, Wisc., USA), $1 \times$ MMLV buffer, $2.5 \mathrm{mM}$ deoxynucleotides (Invitrogen) and 0.3 $\mu \mathrm{M}$ random hexamer oligonucleotides (Bio-Rad Laboratories, Hercules, Calif., USA) in a total volume of $20 \mu \mathrm{l}$. The reaction proceeded for $45 \mathrm{~min}$ at $40^{\circ} \mathrm{C}$ followed by $5 \mathrm{~min}$ at $95^{\circ} \mathrm{C}$. Five microliters of cDNA were used for amplification in a $50-\mu 1$ PCR reaction containing $50 \mu \mathrm{M}$ specific primers, $200 \mu \mathrm{M}$ deoxynucleotides, $25 \mathrm{mM} \mathrm{MgCl}_{2}, 10 \times$ Taq buffer and $1.25 \mathrm{U}$ Taq DNA polymerase (Invitrogen). The PCR primers (sense and antisense) and annealing temperature were as follows: IFN- $\gamma$ : $5^{\prime}$ AGC GGC TGA CTG AAC TCA GAT TGT AG 3', 5' GTC ACA GTT TTC AGC TGT ATA GGG $33^{\prime}, \mathrm{T}_{\mathrm{ann}} 55^{\circ} \mathrm{C}$ [22]; TNF- $\alpha$ : $5^{\prime}$ ATG AGC ACT GAA AGC ATG ATC $3^{\prime}, 5^{\prime}$ TCA CAG GGC AAT GAT CCC AAA GTA GAC CTG C $3^{\prime}, \mathrm{T}_{\text {ann }} 60^{\circ} \mathrm{C}$ [23]; MIF: $5^{\prime}$ CCA TGC CTA TGT TCA TCG TG 3', 5' GAA CAG CGG TGC AGG TAA GTG 3', Tann $55^{\circ} \mathrm{C}$ [24]; iNOS: $5^{\prime}$ AAG CTG CAT GTG ACA TCG ACC CGT $3^{\prime}, 5^{\prime}$ GCA TCT GGT AGC CAG CGT ACC GG $3^{\prime}, \mathrm{T}_{\text {ann }} 58^{\circ} \mathrm{C}$ [25]; CCL5: 5' CGC GGA TCC CCA CGT CAA GGA GTA TTT CTA CAC C 3', 5' CGC GGA TCC CTG GTT TCT TGG GTT TGC TGT G 3', $\mathrm{T}_{\mathrm{ann}} 60^{\circ} \mathrm{C}$ [16]; CXCL9: 5' GAT CAA ACC TGC CTA GAT CC 3', 5' GGC TGT GTA GAA CAC AGA GT 3', T $_{\text {ann }} 54^{\circ} \mathrm{C}$ [16]; CCR5: 5' CAA GAC AAT CCT GAT CGT GCA A 3', 5' TCC TAC TCC CAA GCT GCA TAG AA $3^{\prime}, \mathrm{T}_{\text {ann }} 56^{\circ} \mathrm{C}[26]$, and CXCR3: 5' GCC TTT CTT CTG GAA AAC AGC 3', 5' TGC TGC TCA GGG CAG TGC GC $3^{\prime}, \mathrm{T}_{\mathrm{ann}} 48^{\circ} \mathrm{C}$ [27]. The set of primers used for amplification of the housekeeping $\beta$-actin gene was purchased from Integrated DNA Technologies (Coralville, Iowa, USA). Negative controls consisted of reactions without inclusion of the reverse transcriptase or a target template. Optimization of PCR analyses was accomplished initially by using a variable number of cycles to identify a linear range of amplification for each transcript. The PCR mixture was incubated at $94^{\circ} \mathrm{C}$ for 2 or $5 \mathrm{~min}$ followed by 30 or 35 cycles of amplification. Each cycle consisted of $30 \mathrm{~s}$ or $1 \mathrm{~min}$ of denaturation at $94^{\circ} \mathrm{C}, 30 \mathrm{~s}$ or $1 \mathrm{~min}$ of annealing and 1 or 2 min of extension at $72^{\circ} \mathrm{C}$. The program also included a final extension step at $72^{\circ} \mathrm{C}$ for 7 or $10 \mathrm{~min}$. PCRs were performed in identical conditions for both tissues. Semiquantitative fold induction was calculated as previously described [28]. Briefly, PCR products were electrophoresed on $2 \%$ agarose gels and stained with ethidium bromide. Amplified products were vi- sualized under UV light and quantified with densitometric analysis software (SionImage, version 1.54; National Institutes of Health, Bethesda, Md., USA). The densitometry value for each gene was corrected for the mouse $\beta$-actin value for the same sample. The results are reported as fold increase over uninfected control.

\section{Immunohistochemical Studies}

Immunohistochemical analysis was performed on formalinfixed, paraffin-embedded cardiac and skeletal muscle specimens. Five-micrometer sections were cut onto coated slides and were deparaffinized using routine techniques. After blocking endogenous peroxidase with $3 \%$ hydrogen peroxide and nonspecific binding sites with $2 \%$ bovine serum albumin, the following primary antibodies $(\mathrm{Ab})$ were applied to the sections: rabbit antimouse MIF (Zymed Laboratories, San Francisco, Calif., USA) and CCR5 (Abcam, Cambridge, UK) polyclonal Ab and biotin-labeled rat anti-mouse RANTES/CCL5 monoclonal Ab (R\&D Systems, Minneapolis, Minn., USA). As secondary Ab for MIF and CCR5 detection, we used biotinylated swine anti-rabbit immunoglobulin polyclonal Ab (Dako, Glostrup, Denmark). The reaction product was revealed by streptavidin-horseradish peroxidase complex with diaminobenzidine tetrahydrochloride and hydrogen peroxide chromogen substrate (Dako). The sections were then counterstained with Mayer's hematoxylin and periodic acidSchiff. Omission of the primary Ab and use of isotype-matched control Ab served as controls.

\section{Statistical Analysis}

Data analysis was carried out on a personal computer using GraphPad Prism 4.0 software (GraphPad Software, San Diego, Calif., USA). Arithmetic means and SEM were calculated. Values from uninfected and infected groups were compared using Student's t test. Significant differences among infected groups were analyzed with one-way analysis of variance (ANOVA) followed by Tukey's test or linear trend analysis. p values of 0.05 or less were considered to be significant.

\section{Results}

\section{Parasitemia, Tissue Parasitism and Histopathologic Features}

Low parasitemia was detected in all mice sublethally infected with the RA strain of T. cruzi at 7 DPI, which reached $9.0 \times 10^{5}$ parasites $/ \mathrm{ml}$ of blood at $21 \mathrm{DPI}$ and progressively decreased thereafter (fig. 1a). During the course of acute infection, the level of tissue parasitism and inflammatory responses in the myocardium and skeletal muscle were also determined (fig. 1). At 7 DPI, both tissues lacked histopathologic abnormalities and no intracellular forms of T. cruzi could be demonstrated. In mice killed 1 week later, a diffuse and multifocal inflammatory infiltrate [inflammation score (IS) $=1-2$ ] consisting mainly of lymphoplasmocytic mononuclear cells and macrophages, with fewer polymorphonuclear and mast 
Fig. 1. Parasite load during T. cruzi (RA strain) infection in $\mathrm{BALB} / \mathrm{c}$ mice. $O=$ Heart; $\square=$ skeletal muscle. Means \pm SEM. a Parasitemia (ם). b IS. Similar results were obtained in two other experiments.
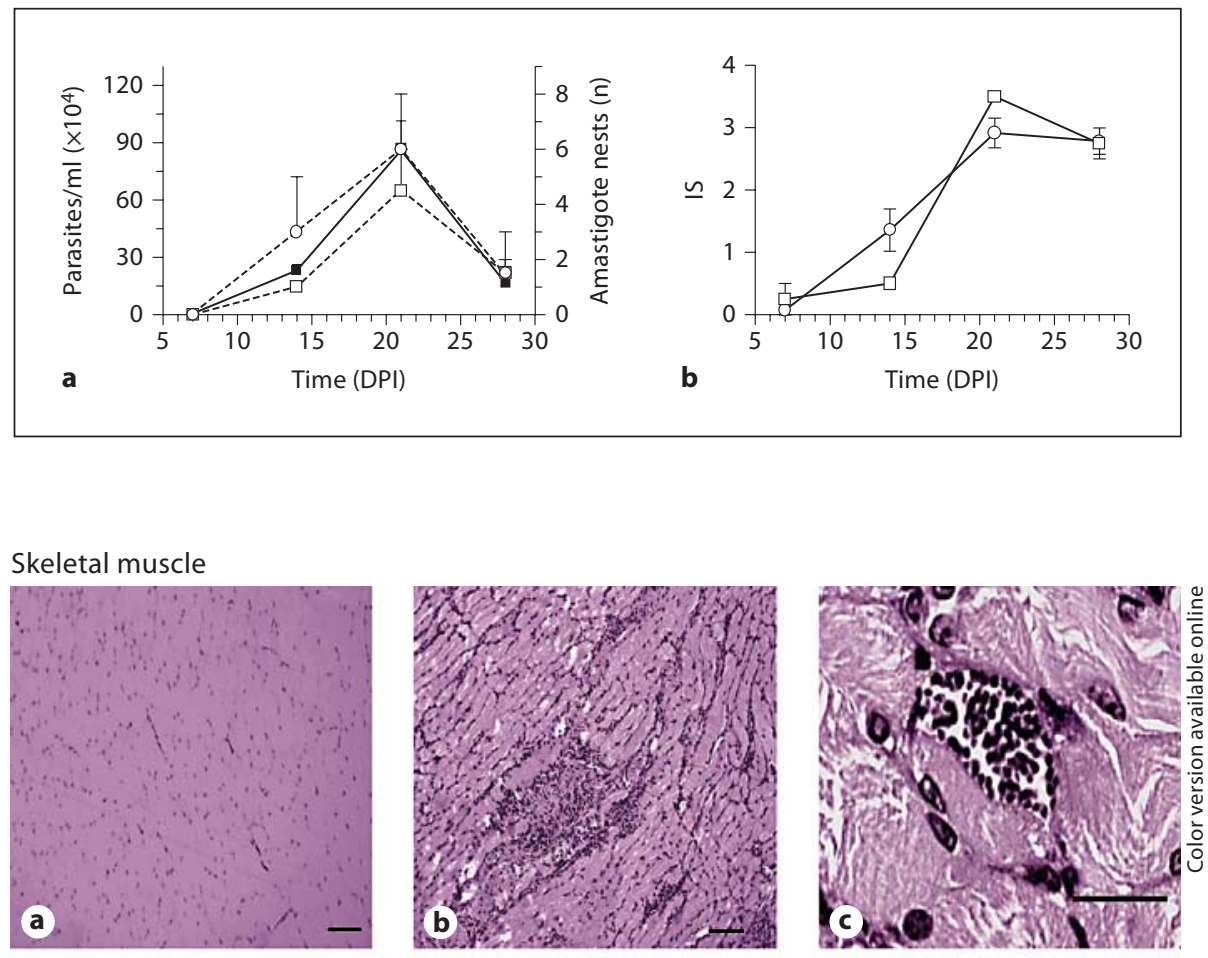

Fig. 2. Tissue inflammation and parasitism in skeletal muscle and heart from BALB/c mice infected with T. cruzi (RA strain). a, d Photomicrographs of 80-dayold uninfected BALB/c mice. b, e Inflammation at 21 days of infection; IS $=3$ in the skeletal muscle and atrium, respectively. c Parasite nest inside an intact skeletal muscle fiber. $\mathbf{f}$ Higher magnification of inflammatory cells in the heart. HE. Bars = 25 (b, c) or $100 \mu \mathrm{m}(\mathbf{a}, \mathbf{d}-\mathbf{f})$.

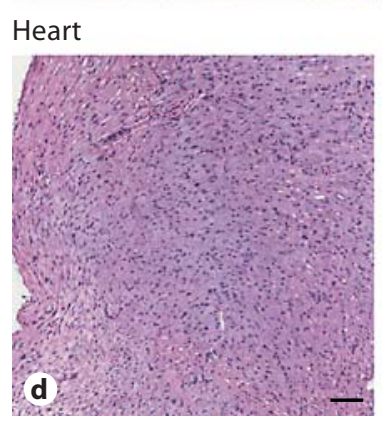

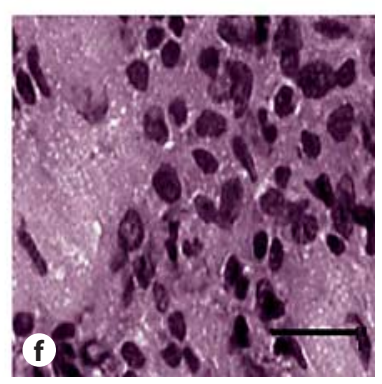

cells, could be observed in $94.5 \%$ of infected hearts. Inflammatory cells were present throughout the organ and affected different heart structures (endocardium, myocardium and epicardium). In skeletal muscle, however, the intensity of inflammation was less evident than in cardiac tissue during this period (IS $=0-1$ ). Inflammatory infiltrates became more dense and extensive between the $3 \mathrm{rd}$ and 4 th week of infection (IS $=3-4$, fig. $1 \mathrm{~b}$, 2). The highest parasite burden within both organs coincided with the peak of parasitemia, maximum severity of myocarditis and presence of intense rhabdomyolysis in $75 \%$ of skeletal muscle samples. Numerous amastigote nests and inflammatory foci were identified in the ventricular wall, also involving the autonomic ganglia and subpericardial tissues.

Chemokine Expression in Skeletal

Muscles from T. cruzi-Infected Mice
Induction of Cytokine and iNOS mRNA Expression in Heart and Skeletal Muscle from BALB/c Mice Infected with T. cruzi $R A$

The results shown in figure 3 illustrate the kinetics of mRNA expression of the proinflammatory cytokines IFN- $\gamma$, TNF- $\alpha$ and MIF in myocardium and skeletal muscle from acutely T. cruzi-infected mice. Only a basal expression of MIF could be demonstrated in specimens from uninfected mice. In both target muscles, an increase in cytokine and iNOS mRNA was observed in the course of the parasitic phase of infection. As early as 7 DPI, MIF expression was strong in skeletal muscle as well as in the heart. mRNA levels of this inflammatory mediator were persistently increased in both tissues throughout the acute episode, even though myocardial expression showed a very significant $(\mathrm{p}<0.001)$ linear 
Fig. 3. Analysis of cytokine and iNOS mRNA expression in skeletal muscle (a) and heart (b) from $B A L B / c$ mice infected with T. cruzi (RA strain) based on RTPCR. Each lane of the gel corresponds to the result of RT-PCR obtained from a single animal, representative of all mice at the indicated time of infection. Values are normalized to the mRNA levels in uninfected animals (control group). Means \pm SEM. Similar results were obtained in two other experiments. ${ }^{*} \mathrm{p}<0.05,{ }^{* *} \mathrm{p}<0.01$, $*^{* *} \mathrm{p}<0.001$, infected vs. uninfected animals $(\mathrm{n}=5)$.
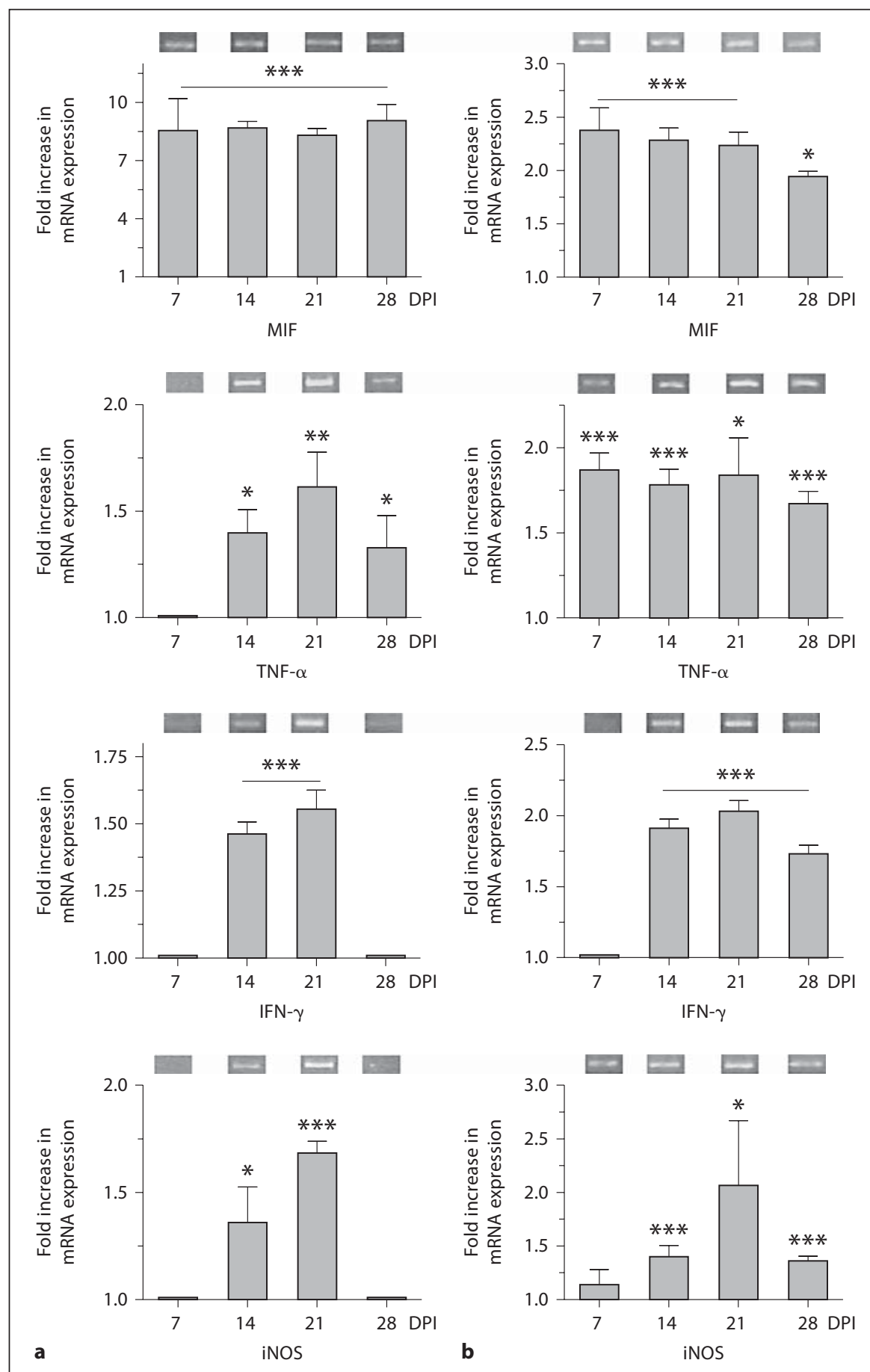

trend to decrease. In the heart, prompt MIF induction was accompanied by enhanced TNF- $\alpha$ expression, which remains constant through day 28 , whereas in striated muscle TNF- $\alpha$ transcripts were demonstrated between 14 and 28 DPI. Likewise, the overall expression kinetics of iNOS and IFN- $\gamma$ in cardiac tissues presented increased values 14, 21 and $28 \mathrm{DPI}$. Additionally, the induction of muscular expression of both the enzyme and the proinflammatory cytokine became apparent at 14-21 days of infection. 
Fig. 4. Analysis of chemokine and chemokine receptor mRNA expression in skeletal muscle (a) and heart (b) from BALB/c mice infected with $T$. cruzi (RA strain) based on RT-PCR. Each lane of the gel corresponds to the result of RT-PCR obtained from a single animal representative of all mice at the indicated time of infection. Values are normalized to the mRNA levels in uninfected animals (control group). Means \pm SEM. Similar results were obtained in two other experiments. ${ }^{*} \mathrm{p}<$ $0.05,{ }^{* *} \mathrm{p}<0.01,{ }^{* * *} \mathrm{p}<0.001$, infected vs. uninfected animals $(\mathrm{n}=5)$.
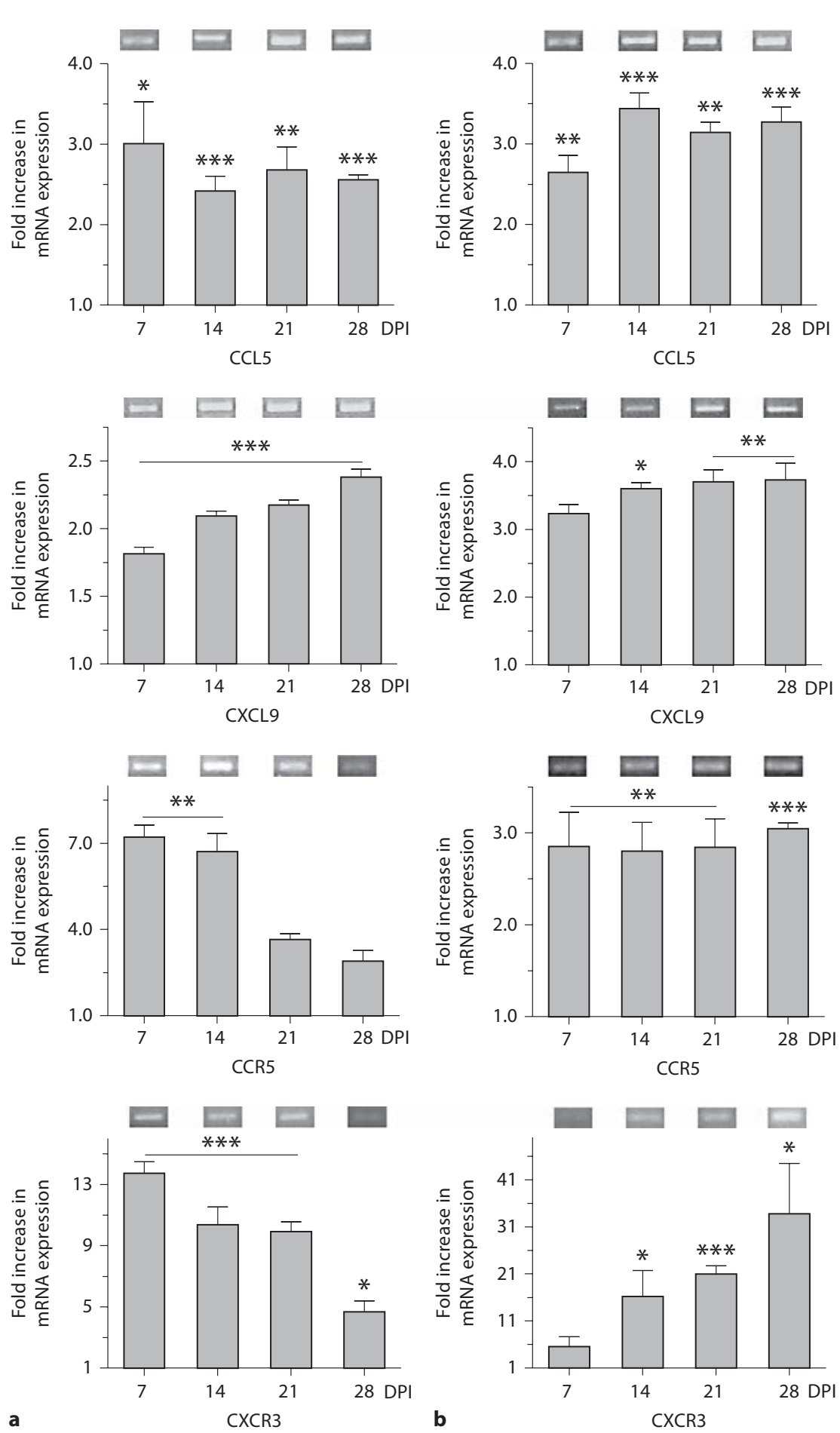
Fig. 5. Expression of MIF, CCL5 and CCR 5 proteins in skeletal muscle and heart from BALB/c mice infected with T. cruzi (RA strain). Representative results of immunohistochemical analysis. MIF and CCL5 expression was determined at $21 \mathrm{DPI}$, whereas CCR 5 expression was determined at 14 DPI. a, d, f, h, k, $\mathbf{n}$ Specimens from uninfected mice. b, c MIF immunostaining in striated muscles. Note positive labeling for MIF as intracellular deposits in both myocytes (b) and infiltrating cells (c). e MIF immunostaining in myocardium. Note the intense immunoreactivity at the leukocyte infiltrate and in the cardiomyocytes. g CCL5 immunolabeling in skeletal muscle revealing infiltrating cells and myocytes. i, j CCL5 immunolabeling displaying specific reactivity in auricular (i) and ventricular (j) myocardium. I, m CCR5 immunostaining in striated muscle; labeling for infiltrating cells and myofibers can be observed. o CCR5 immunostaining in the heart; positive reaction is localized at the inflammatory infiltrate. The positive staining in muscle cells is indicated by arrows. Original magnification for all microphotographs $\times 400$. Bar $=50 \mu \mathrm{m}$.
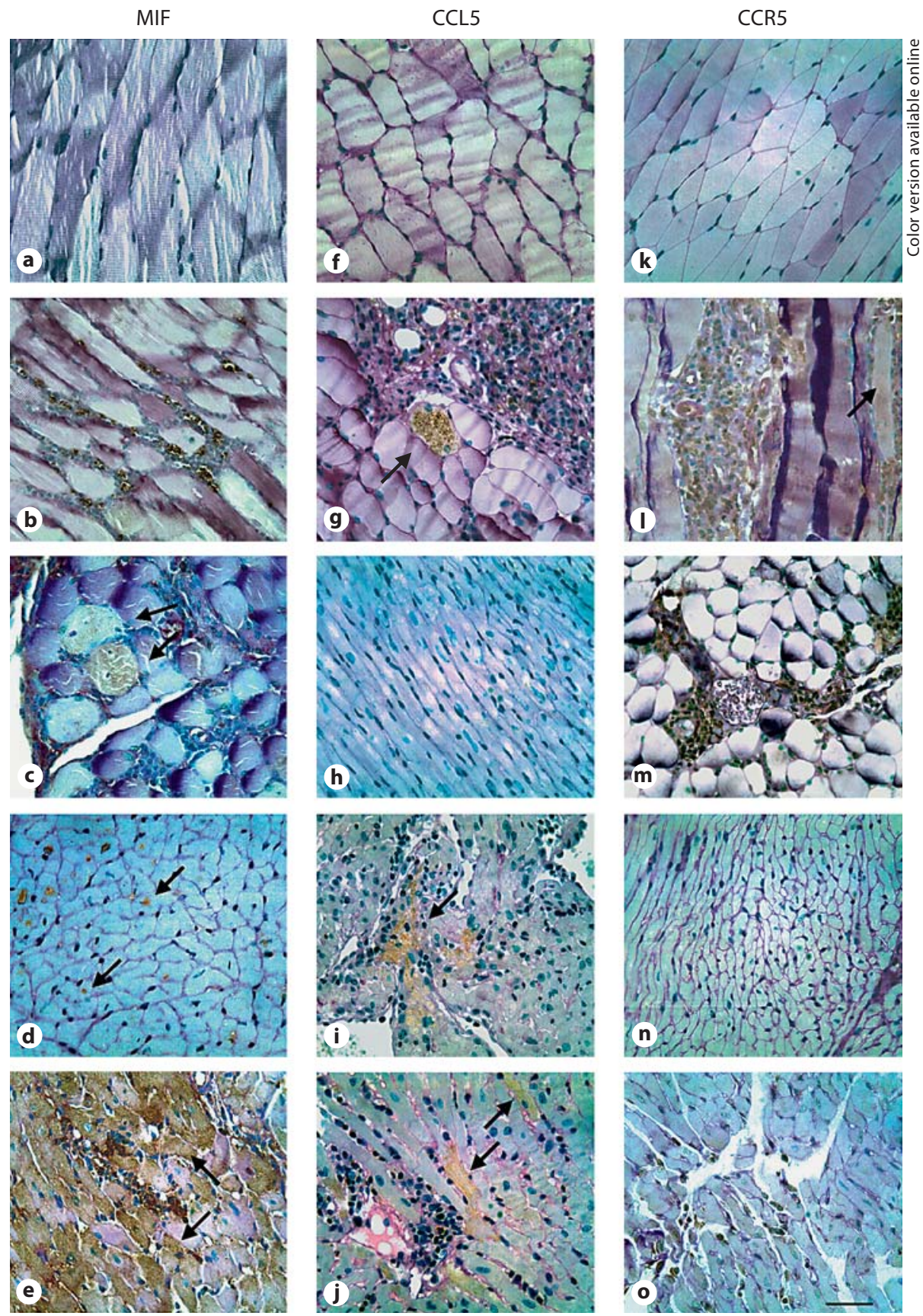

Induction of Chemokine and Chemokine Receptor $m R N A$ Expression in Heart and Skeletal Muscle from $B A L B / c$ Mice Infected with T. cruzi RA

We next assessed the temporal mRNA expression of type 1 response-linked chemokines (CCL5 and CXCL9) and their receptors (CCR5 and CXCR3) in myocardium and skeletal muscle from acutely T. cruzi-infected mice (fig. 4). Reduced expression of chemokines and chemo- kine receptors was measured in specimens from uninfected mice. Myocardial CCL5 mRNA expression was induced since day 7 of infection, with continued upregulation to day 28. A similar CCL5 expression profile was observed in striated muscle, with increased transcripts at all time points examined after parasite infection. In acutely infected hearts, CCR5 mRNA levels remained consistently elevated, whereas muscular expression of 
this chemokine receptor was induced transiently (7-14 DPI). Regarding the CXC chemokine subfamily, in myocardium we found enhanced production of transcripts for CXCL9 between 14 and 28 DPI, also demonstrable in skeletal muscle even at earlier times of infection (since day 7). Moreover, in both target tissues, CXCL9 expression displayed a significant $(\mathrm{p}<0.001)$ positive trend throughout the acute episode. Like its chemokine ligand, heart CXCR3 receptor expression was induced during the initial stage of experimental Chagas' disease (14-28 DPI). In contrast, muscular CXCR3 gene expression was promptly (7 DPI) upregulated but subsided by day 28 of infection.

\section{MIF, CCL5 and CCR5 Proteins Are Present at}

Inflammation Sites in Heart and Skeletal Muscle from

$B A L B / c$ Mice Infected with T. cruzi RA

To confirm that the differences observed in gene expression were also evident at the protein level and biologically relevant, an immunohistochemical evaluation of some of these inflammatory mediators was carried out by expert pathologists. MIF, CCL5 and CCR5 expression was upregulated in the lesions of the myocardium and striated muscle following acute T. cruzi infection in mice (fig. 5). Immunoreactivity for MIF and CCL5 could be detected at 21 DPI in the cardiac and skeletal myocytes as well as in the infiltrating leukocytes (fig. 5a-j). In the striated muscle, CCR 5 was expressed by both cell types at 14 DPI, whereas myocardial immunolabeling of this receptor was restricted to inflammatory infiltrates except for myofibers (fig. 5k-o).

\section{Discussion}

Chagas' disease is caused by persistent T. cruzi infection in muscle cells that ultimately results in chronic inflammation and tissue destruction. Although this human parasitosis is known to provoke severe acute myositis $[29,30]$, accurate information on cytokine and chemokine overexpression associated with the pathogenesis in skeletal muscle is currently missing. In the present study, we report on the transcription of a set of proinflammatory cytokines and chemokines by different muscles during acute T. cruzi infection, to better understand their participation in the development of parasite-induced inflammatory myopathy. Particularly, the RA strain of T. cruzi has been proven to promote neuromyopathic inflammatory lesions in acutely infected mice, with predominance of $\mathrm{CD} 8+\mathrm{T}$ cells in leukocyte infil- trates [19]. In agreement with previous findings [16, 31, 32], acute myocarditis and intense rhabdomyolysis developed during the initial phase of experimental Chagas' disease. Muscle cells may be actively involved in the recruitment of mononuclear cells from the bloodstream and in the cross-talk between infiltrating leukocytes and myocytes, mediated by active transcription and release of cytokines and chemokines by both cell types, creating the conditions for ongoing inflammation [33]. Several of these inflammatory mediators expressed in the muscles are relevant in the containment of parasite dissemination soon after infection; however, the parasite is capable of deregulating the host's inflammatory response, thus extending it beyond the area of the original injury [15].

In general, the timing of enhanced TNF- $\alpha$, IFN- $\gamma$ and iNOS gene expression paralleled the course of parasitemia and the intensity of the parasite burden and inflammatory reaction within the infected muscles. Of note, relative increases in mRNA levels can provide an indication of, but not necessarily reflect, enhanced protein production. These factors presented slightly different kinetics of expression in both target organs during the acute stage of infection. In striated muscle, TNF- $\alpha$ mRNA expression could be detected 1 week later with respect to the very early induction of this proinflammatory cytokine in the heart, whereas triggering of IFN- $\gamma$ and iNOS messages appears to be more transient than that observed in cardiac tissues. Throughout the parasitic phase of infection, MIF mRNA transcripts were significantly increased at both body sites, reaching higher levels in skeletal muscle. To the best of our knowledge, this is the first report documenting MIF induction in inflamed target tissues from T. cruzi-infected hosts. Upon direct microbial or cytokine-mediated stimulation, this proinflammatory cytokine can be released by a panel of cell types, including leukocytes and myocytes. In our series, augmented MIF gene expression was detected since day 7 of infection, indicating its involvement in the primary response against the parasite. Increased MIF anticipated the induction of other proinflammatory cytokines, suggesting that MIF could be located upstream from both TNF- $\alpha$ and IFN- $\gamma$ in the activating cascade. In a recent study, Reyes et al. [5] reported that MIF plays an important role in host defense against acute T. cruzi infection by favoring early production of Th1-type cytokines and NO. Nevertheless, like other proinflammatory cytokines, we found that MIF may also be present in association with a state of muscle inflammation and rhabdomyolysis shortly after infection. 
In an attempt to evaluate some of the components of the chemokine system in murine acute Chagas' disease, myocardial and muscular parasitism was accompanied by inflammation and upregulated expression of several chemokines and chemokine receptors in our study. CCL5 and CCR5 are considered essential for killing of intracellular forms of T. cruzi and effective control of acute infection [17], but IFN- $\boldsymbol{\gamma}$-inducible chemokines and chemokine receptors have also been linked to inflammatory myopathies [33]. In particular, our observation of enhanced CCR5 expression in the infected muscles is consistent with its important role in promoting leukocyte infiltration within target organs as well as limiting parasite replication during early $T$. cruzi infection, previously reported by Hardison et al. [34]. Compared to the heart, skeletal muscles showed a distinctive timing of gene expression of these inflammatory mediators. Remarkably, for CCL5/CCR5, as well as for CXCL9/CXCR3, both ligand and receptor displayed differential kinetics of expression in striated muscle suggesting that it may alternatively be modulated by chemokine and chemokine receptors other than those analyzed in our study.

CXCL9 has been found to promote a protective anti-T. cruzi response, but also to contribute to the genesis of parasite-induced megaesophagus and cardiomyopathy $[16,32,35]$. Besides, in chronic Chagas heart disease patients, other authors demonstrated dominant expression of CXCR 3 and CCR 5 by IFN- $\gamma$ - and/or TNF- $\alpha$-producing CD4+ or CD8+ T cells [36]. CXCL9 and CXCR3 mRNA expression levels seem to rise earlier in striated muscle than in the heart of T. cruzi RA-infected mice. Further, transcripts for this proinflammatory chemokine in both tissues showed a linear trend to increase along with the evolution of infection towards the chronic stage. Conversely, CXCR3 mRNA levels in skeletal muscle, but not in the myocardium, rapidly peaked and then decreased during the initial course of experimental Chagas' disease. CXCL9/CXCR3 and CCL5/CCR5 expression is induced by the overproduction of IFN- $\gamma$, TNF- $\alpha$ or IL-12 that occurs upon T. cruzi infection of mice $[2,15]$. Nevertheless, we recorded enhanced mRNA levels of these chemokines and chemokine receptors in the inflamed muscles even when IFN- $\gamma$ and TNF- $\alpha$ expression appeared very decreased or undetectable. This observation suggests that alternative factors, such as parasite components or different immune mediators, could also be responsible for the regulation of the chemokine system during the acute episode.

Early T. cruzi infection in mice induces the transcription of a set of inflammatory mediators, but can also trig- ger their protein expression at target tissues. Immunohistochemical analysis of the infected muscles confirmed that proinflammatory cytokines, chemokines and their receptors, such as MIF, CCL5 and CCR5, are present at inflammation sites in heart and skeletal muscle from acutely infected mice. These molecules seem to be highly expressed by myofibers and infiltrating lymphocytes, except for CCR 5 overexpression in cardiac tissues, which appears to be restricted to the inflammatory infiltrates. This observation is in agreement with previous studies where CCR5 expression was associated with CD8+ T cells in heart lesions provoked by T. cruzi infection [37]. On the other hand and similar to our finding in the infected myocytes, CCR 5 has been shown to be abundantly expressed on skeletal muscle cells after traumatic injury [38]. Therefore, during acute parasite infection, muscle cells themselves may also have an active role in the inflammatory process, not only by producing cytokines/ chemokines, but also by expressing chemokine receptors like CCR5. Several reports indicate that, beside recruitment of circulating leukocytes, chemokines and their receptors may mediate other biological effects with relevance to the pathogenesis of muscular disorders, such as induction of cell proliferation [39] and apoptosis [40].

Proinflammatory cytokines and chemokines have long been linked to immune mechanisms leading to the early control of experimental T. cruzi infection [3, 15]. Noticeably, our findings show that the peak of parasitemia and tissue parasitism in T. cruzi RA-infected BALB/ c mice occurs around day 21 , yet practically all chemokine/chemokine receptor gene expression levels are most drastically upregulated on day 7 , remaining elevated or further increasing throughout the acute period. It may be considered that this prompt chemokine response is insufficient to achieve an effective killing of both circulating and intracellular parasites, which further requires the combined overexpression of IFN- $\gamma$, TNF- $\alpha$ and iNOS [41] recorded at the $3 \mathrm{rd}$ week of infection. Interestingly, previous studies [42] demonstrated that $\mathrm{CD} 3+, \mathrm{CD} 4 / \mathrm{CD} 8$ double-negative $\mathrm{T}$ cells present in muscles from T. cruziinfected $\mathrm{BALB} / \mathrm{c}$ mice $15 \mathrm{DPI}$ display regulatory features that might delay and/or downmodulate local trypanocidal activity. Moreover, induction of the chemokine system may also provoke detrimental consequences for the host during infection with protozoan parasites. CXCR3 and CCR1 have been reported to play a role in immunopathogenesis of cutaneous leishmaniasis, while high expression of splenic CCL2 has been demonstrated to contribute to sustained parasite load in Leishmania infantum-infected BALB/c mice [43-45]. 
So far, information is unavailable with regard to the participation of inflammatory chemokines and chemokine receptors in the development of T. cruzi-elicited striated muscle lesions. In the present study, during the parasitic phase of infection, we found early induction of muscular expression for CCL5/CCR5 and CXCL9/ CXCR3, accompanied by the severity of parasite burden and myopathy. These molecules, together with IFN- $\gamma$, TNF- $\alpha$ and TGF- $\beta$, might participate in the selective recruitment of CD8+ T lymphocytes involved in the immunopathogenesis of muscle inflammation observed in experimental acute Chagas' disease [31]. Further studies may provide additional insights into the recognition of those components of the cytokine/chemokine network which are essential for parasite control in the infected host and/or contribute to T. cruzi-dependent inflammatory damage to skeletal muscles.

\section{Acknowledgments}

This work was supported by grants from the National Research Council (CONICET, Argentina). R.S.C, P.B.P. and M.P. are members of the Research Career Program from CONICET. R.A.C. thanks Bunge \& Born Foundation (Buenos Aires, Argentina) and CONICET for fellowships granted. T. cruzi (RA strain) was kindly provided by Dr. S.M. González Cappa (University of Buenos Aires).

\section{References}

1 Morel CM, Lazdins J: Chagas' disease. Nat Rev Microbiol 2003;1:14-15.

2 DosReis GA: Cell-mediated immunity in experimental Trypanosoma cruzi infection. Parasitol Today 1997;13:335-342.

-3 Abrahamsohn IA: Cytokines in innate and acquired immunity to Trypanosoma cruzi infection. Braz J Med Biol Res 1998;31:117121.

-4 Petray P, Rottenberg ME, Grinstein S, Örn A: Release of nitric oxide during the experimental infection with Trypanosoma cruzi. Parasite Immunol 1994;16:193-199.

5 Reyes JL, Terrazas LI, Espinoza B, Cruz-Robles D, Soto V, Rivera-Montoya I, GómezGarcía L, Snider H, Satoskar AR, RodríguezSosa M: Macrophage migration inhibitory factor contributes to host defense against acute Trypanosoma cruzi infection. Infect Immun 2006;74:3170-3179.

$\checkmark 6$ Yacoub S, Mocumbi AO, Yacoub MH: Neglected tropical cardiomyopathies: I. Chagas disease: myocardial disease. Heart 2008;94: 244-248.

-7 Laguens RP, Cossio PM, Diez C, Segal A, Vasquez C, Kreutzer E, Khoury E, Arana RM: Immunopathologic and morphologic studies of skeletal muscle in Chagas' disease. Am J Pathol 1975;80:153-162.

-8 Higuchi ML, Benvenuti LA, Martins Reis M, Metzger M: Pathophysiology of the heart in Chagas' disease: current status and new developments. Cardiovasc Res 2003;60:96107.

9 Teixeira AR, Monteiro PS, Rebelo JM, Arganaraz ER, Vieira D, Lauria-Pires L, Nascimento R, Vexenat CA, Silva AR, Ault SK, Costa JM: Emerging Chagas' disease: trophic network and cycle of transmission of Trypanosoma cruzi from palm trees in the Amazon. Emerg Infect Dis 2001;7:100-112.
10 Brener Z, Gazzinelli RT: Immunological control of Trypanosoma cruzi infection and pathogenesis of Chagas' disease. Int Arch Allergy Immunol 1997;114:103-110.

-11 Mirkin GA, Celentano AM, Malchiodi EL, Jones M, González Cappa SM: Different Try panosoma cruzi strains promote neuromyopathic damage mediated by distinct $\mathrm{T}$ lymphocyte subsets. Clin Exp Immunol 1997; 107:328-334.

12 Chensue SW: Molecular machinations: chemokine signals in host-pathogen interactions. Clin Microbiol Rev 2001;14:821-835.

13 Almeida IC, Gazzinelli RT: Proinflammatory activity of glycosylphosphatidylinosito anchors derived from Trypanosoma cruzi: structural and functional analyses. J Leukoc Biol 2001;70:467-477.

14 Brown WC, Corral RS: Stimulation of B lymphocytes, macrophages, and dendritic cells by protozoan DNA. Microbes Infect 2002;4 969-974.

15 Teixeira MM, Gazzinelli RT, Silva JS: Chemokines, inflammation and Trypanosoma cruzi infection. Trends Parasitol 2002;18: 262-265.

16 Talvani A, Ribeiro CS, Aliberti JC, Michailowsky V, Santos P, Murta S, Romanha A, Almeida I, Farber J, Lannes-Vieira J, Silva J, Gazzinelli R: Kinetics of cytokine gene expression in experimental chagasic cardiomyopathy: tissue parasitism and endogenous IFN- $\gamma$ as important determinants of chemokine mRNA expression during infection with Trypanosoma cruzi. Microbes Infect 2000;2:851-866.

17 Marino AP, Silva AA, Santos PVA, Pintos LMO, Gazinelli RT, Teixeira MM, LannesVieira J: CC-chemokine receptors: a potential therapeutic target for Trypanosoma cru$z i$-elicited myocarditis. Mem Inst Oswaldo Cruz 2005;100(suppl 1):93-96.
18 Talvani A, Rocha MOC, Ribeiro AL, CorreaOliveira R, Teixeira MM: Chemokine receptor expression on the surface of peripheral blood mononuclear cells in Chagas disease. J Infect Dis 2004;189:214-220.

19 Mirkin GA, Jones M, Sanz OP, Rey R, Sica RE, González Cappa SM: Experimental Chagas' disease: electrophysiology and cell composition of the neuromyopathic inflammatory lesions in mice infected with a myotropic and a pantropic strain of Trypanosoma cruzi. Clin Immunol Immunopathol 1994;73:69-79.

20 González Cappa SM, Bijovsky SAT, Freilij H, Müller LA, Katzin AM: Aislamiento de una cepa de Trypanosoma cruzi a predominio de formas delgadas en la Argentina. Medicina (B Aires) 1981;41:119-120.

21 Postan M, Dvorak JA, McDaniel JP: Studies of Trypanosoma cruzi clones in inbred mice. I. A comparison of the course of infection of $\mathrm{C} 3 \mathrm{H} / \mathrm{HEN}-$ mice with two clones isolated from a common source. Am J Trop Med Hyg 1983;32:497-506.

22 Sasaki S, Miura T, Nishikawa S, Yamada K, Hirasue M, Nakane A: Protective role of nitric oxide in Staphylococcus aureus infection in mice. Infect Immun 1998;66:1017-1022.

23 Laucella S, Salcedo R, Castaños-Velez E, Riarte A, De Titto EH, Patarroyo M, Örn A, Rottenberg ME: Increased expression and secretion of ICAM-1 during experimental infection with Trypanosoma cruzi. Parasite Immunol 1996;18:227-239.

24 Bernhagen J, Calandra T, Mitchell RA, Martin SB, Tracey KJ, Voelter W, Manogue KR, Cerami A, Bucala R: MIF is a pituitary-derived cytokine that potentiates lethal endotoxaemia. Nature 1993;365:756-759. 
25 Revelli S, Le Page C, Piaggio E, Wietzerbin J, Bottasso O: Benznidazole, a drug employed in the treatment of Chagas' disease, downregulates the synthesis of nitrite and cytokines by murine stimulated macrophages. Clin Exp Immunol 1999;118:271-277.

26 Zhang N, Schröppel B, Chen D, Fu S, Hudkins KL, Zhang H, Murphy BM, Sung RS, Bromberg JS: Adenovirus transduction induces expression of multiple chemokines and chemokine receptors in murine $\beta$ cells and pancreatic islets. Am J Transplant 2003; 3:1230-1241.

27 Nagpal ML, Chen Y, Lin T: Effects of overexpression of CXCL10 (cytokine-responsive gene-2) on MA-10 mouse Leydig tumor cell steroidogenesis and proliferation. J Endocrinol 2004;183:585-594.

-28 Kimura N, Kumamoto T, Kawamura Y, Himeno T, Nakamura K, Ueyama H, Arakawa $\mathrm{R}$ : Expression of autophagy-associated genes in skeletal muscle: an experimental model of chloroquine-induced myopathy. Pathobiology 2007;74:169-176.

-29 von Kreuter BF, Santos-Buch CA: Pathoimmune polymyositis induced in $\mathrm{C} 3 \mathrm{H} / \mathrm{HeJ}$ mice by Trypanosoma cruzi infection. Clin Exp Rheumatol 1986;4:83-89.

-30 Molina HA, Cardoni RL, Rimoldi MT: The neuromuscular pathology of experimental Chagas' disease. J Neurol Sci 1987;81:287300

\$1 Magalhães-Santos IF, Andrade SG: Participation of cytokines in the necrotic-inflammatory lesions in the heart and skeletal muscles of Calomys callosus infected with Trypanosoma cruzi. Mem Inst Oswaldo Cruz 2005;100:555-561.
-32 Hardison JL, Wrightsman RA, Carpenter PM, Lane TE, Manning JE: The chemokines CXCL9 and CXCL10 promote a protective immune response but do not contribute to cardiac inflammation following infection with Trypanosoma cruzi. Infect Immun 2006;74:125-134.

33 De Rossi M, Bernasconi P, Baggi F, de Waal Malefyt R, Mantegazza R: Cytokines and chemokines are both expressed by human myoblasts: possible relevance for the immune pathogenesis of muscle inflammation. Int Immunol 2000;12:1329-1335.

34 Hardison JL, Wrightsman RA, Carpenter PM, Kuziel WA, Lane TE, Manning JE: The CC chemokine receptor 5 is important in control of parasite replication and acute cardiac inflammation following infection with Trypanosoma cruzi. Infect Immun 2006;74: 135-143.

- 35 Crema E, de Oliveira Monteiro I, Zainer Gomes MG, Silva AA, Rodrigues Júnior V: Evaluation of cytokines (MIG, IFN- $\gamma$, TNF$\alpha$, IL-4, IL-5 and IL-10) during the different evolutive phases of chagasic esophagopathy. Clin Immunol 2006;119:213-218.

36 Gomes JAS, Bahia-Oliveira LMG, Rocha MOC, Busek SCU, Teixeira MM, Silva JS, Correa-Oliveira R: Type 1 chemokine receptor expression in Chagas correlates with morbidity in cardiac patients. Infect Immun 2005;73:7960-7966

-37 Machado FS, Koyama NS, Carregaro V, Ferreira BR, Milanezi CM, Teixeira MM, Rossi MA, Silva JS: CCR5 plays a critical role in the development of myocarditis and host protection in mice infected with Trypanosoma cru$z i$. J Infect Dis 2005;191:627-636.

-38 Warren GL, O’ Farrell L, Summan M, Hulderman T, Mishra D, Luster MI, Kuziel WA, Simeonova PP: Role of CC chemokines in skeletal muscle functional restoration after injury. Am J Physiol Cell Physiol 2004;286: C1031-C1036.
39 Luster AD: Chemokines - chemotactic cytokines that mediate inflammation. N Engl J Med 1998;338:436-445.

40 Hesselgesser J, Taub D, Baskar P, Greenberg M, Hoxie J, Kolson DL, Horuk R: Neuronal apoptosis induced by HIV-1 gp120 and the chemokine SDF-1 alpha is mediated by the chemokine receptor CXCR4. Curr Biol 1998; 8:595-598.

-41 Muñoz-Fernández MA, Fernández MA, Fresno M: Synergism between tumor necrosis factor-alpha and interferon-gamma on macrophage activation for the killing of intracellular Trypanosoma cruzi through a nitric oxide-dependent mechanism. Eur J Immunol 1992;22:301-307.

42 Melo de Oliveira G, Diniz RL, Batista W, Batista MM, Bani Correa C, de Araújo-Jorge TC, Henriques-Pons A: Fas ligand-dependent inflammatory regulation in acute myocarditis induced by Trypanosoma cruzi infection. Am J Pathol 2007;171:79-86.

$\checkmark 43$ Rousseau D, Demartino S, Anjuère F, Ferrua B, Fragaki K, Le Fichoux Y, Kubar J: Sustained parasite burden in the spleen of Leishmania infantum-infected $\mathrm{BALB} / \mathrm{c}$ mice is accompanied by expression of MCP-1 transcripts and lack of protection against challenge. Eur Cytokine Netw 2001;12:340347.

44 Rodriguez-Sosa M, Rosas LE, Terrazas LI, Lu B, Gerard C, Satoskar AR: CC chemokine receptor 1 enhances susceptibility to Leishmania major during early phase of infection. Immunol Cell Biol 2003;81:114-120.

45 Rosas LE, Barbi J, Lu B, Fujiwara Y, Gerard C, Sanders VM, Satoskar AR: CXCR3-/mice mount an efficient Th1 response but fail to control Leishmania major infection. Eur J Immunol 2005;35:515-523. 